\title{
Epidemiology and impact of chronic bronchitis in chronic obstructive pulmonary disease
}

\author{
Lies Lahousse ${ }^{1,2}$, Leen J.M. Seys ${ }^{1,3}$, Guy F. Joos ${ }^{1}$, Oscar H. Franco², \\ Bruno H. Stricker ${ }^{2,4,5}$ and Guy G. Brusselle $1,2,6$
}

Affiliations: ${ }^{1}$ Dept of Respiratory Medicine, Ghent University and Ghent University Hospital, Ghent, Belgium. ${ }^{2}$ Dept of Epidemiology, Erasmus Medical Center, Rotterdam, The Netherlands. ${ }^{3}$ Laboratory of Immunoregulation and Mucosal Immunology, VIB-UGent Center for Inflammation Research, Ghent, Belgium. ${ }^{4}$ Member of the Netherlands Consortium on Healthy Aging (NCHA). ${ }^{5}$ Inspectorate of Healthcare, The Hague, The Netherlands. ${ }^{6}$ Dept of Respiratory Medicine, Erasmus Medical Center, Rotterdam, The Netherlands.

Correspondence: Guy G. Brusselle; Dept of Epidemiology, Erasmus MC, PO Box 2040; 3000 CA Rotterdam, the Netherlands. E-mail: g.brussellederasmusmc.nl

@ERSpublications

Chronic bronchitis increases the risk of exacerbations and mortality among patients with COPD http://ow.ly/o1fq30bFf9Q

Cite this article as: Lahousse L, Seys LJM, Joos GF, et al. Epidemiology and impact of chronic bronchitis in chronic obstructive pulmonary disease. Eur Respir J 2017; 50: 1602470 [https://doi.org/10.1183/ 13993003.02470-2016].

ABSTRACT Research on the association between chronic bronchitis and chronic obstructive pulmonary disease (COPD) exacerbations has led to discordant results. Furthermore, the impact of chronic bronchitis on mortality in COPD subjects is unclear.

Within the Rotterdam Study, a population-based cohort study of subjects aged $\geqslant 45$ years, chronic bronchitis was defined as having a productive cough for $\geqslant 3$ months per year for two consecutive years. Linear, logistic regression and Cox proportional hazard models were adjusted for age, sex and pack-years.

Out of 972 included COPD subjects, 752 had no chronic phlegm production $\left(\mathrm{CB}^{-}\right)$and 220 had chronic phlegm production, of whom 172 met the definition of chronic bronchitis $\left(\mathrm{CB}^{+}\right) \cdot \mathrm{CB}^{+}$subjects were older, more frequently current smokers and had more pack-years than $\mathrm{CB}^{-}$subjects. During a median 6.5 years of followup, $\mathrm{CB}^{+}$subjects had greater decline in lung function $\left(-38 \mathrm{~mL} \cdot \mathrm{year}^{-1}, 95 \% \mathrm{CI}-61.7--14.6\right.$; $\left.\mathrm{p}=0.024\right)$. $\mathrm{CB}^{+}$ subjects had an increased risk of frequent exacerbations (OR 4.0, 95\% CI 2.7-5.9; $\mathrm{p}<0.001$ ). In females, survival was significantly worse in $\mathrm{CB}^{+}$subjects compared to $\mathrm{CB}^{-}$subjects. Regarding cause-specific mortality, $\mathrm{CB}^{+}$ subjects had an increased risk of respiratory mortality (hazard ratio 2.16, 95\% CI 1.12-4.17; $\mathrm{p}=0.002$ ).

COPD subjects with chronic bronchitis have an increased risk of exacerbations and respiratory mortality compared to COPD subjects without chronic phlegm production.

This article has supplementary material available from erj.ersjournals.com

Received: Dec 162016 | Accepted after revision: May 022017

Support statement: Lies Lahousse is a postdoctoral fellow of the Research Foundation - Flanders (FWO). This study was supported by FWO projects G035014N and G089712N, the Concerted Research Action of the Ghent University (BOF/ GOA, 01G02714) and the Interuniversity Attraction Poles programme (IUAP, P7/30). The Rotterdam Study is supported by the Erasmus MC and Erasmus University Rotterdam; the Netherlands Organisation for Scientific Research (NWO); the Netherlands Organisation for Health Research and Development (ZonMW); the Research Institute for Diseases in the Elderly (RIDE); the Netherlands Genomics Initiative; the Ministry of Education, Culture and Science; the Ministry of Health, Welfare and Sports; the European Commission (DG XII); and the Municipality of Rotterdam. The funding source had no involvement in the collection, analysis, writing, interpretation, or in the decision to submit the paper for publication. Funding information for this article has been deposited with the Crossref Funder Registry.

Conflict of interest: Disclosures can be found alongside this article at erj.ersjournals.com

Copyright CERS 2017. This ERJ Open article is open access and distributed under the terms of the Creative Commons Attribution Non-Commercial Licence 4.0. 


\section{Introduction}

Progressive, incompletely reversible airflow limitation is the main characteristic of chronic obstructive pulmonary disease (COPD) [1]. Clinical presentation, response to therapy and disease progression are heterogeneous among patients with COPD [1]. Patients with COPD suffer to varying degrees from chronic cough, expectoration of phlegm, dyspnoea and a variety of extrapulmonary symptoms. Identifying and studying subgroups of patients with similar traits within the COPD syndrome can aid in guiding more individualised therapy and assessment of prognosis [2]. Several COPD phenotypes have been proposed, but only a few have been validated [3]. One of these COPD phenotypes is the chronic bronchitis (CB) phenotype, which is generally defined as patients with COPD who experience chronic cough and sputum production for $\geqslant 3$ months per year for two consecutive years [4].

Observational studies linking the chronic bronchitis phenotype in COPD to outcomes have generated inconsistent results regarding exacerbations and mortality. Both outcomes are crucial since they have a substantial impact on the burden of disease [1]. Although COPD is a chronic disease, acute exacerbations and the rate at which they occur determine the progression of the disease [5]. Because COPD exacerbations have been associated with impaired quality of life $[6,7]$, accelerated deterioration of lung function [8,9], increased risk of hospital admission [10] and increase in mortality [11], they have an important impact on the healthcare-related costs [3]. Two large-scale studies in Global Initiative for Chronic Obstructive Lung Disease (GOLD) stage II-IV COPD patients with $\geqslant 10$ pack-years of smoking history have reported on the association between chronic bronchitis and exacerbations, with opposing results: the Evaluation of COPD Longitudinally to Identify Predictive Surrogate End-points (ECLIPSE) study ( $\mathrm{n}=2138$ ) did not find an association between chronic bronchitis and (medically treated) COPD exacerbations during the first year of follow-up, whereas the COPDGene study $(n=1061)$ detected a strong association between chronic bronchitis and self-reported exacerbation history [12-14]. Other smaller patient-based studies contribute to these discordant results by observing the absence as well as the presence of an association between chronic bronchitis and exacerbation history [15-18]. In contrast, observations from population-based studies are scarce and evaluated only COPD hospitalisations or a self-reported exacerbation history $[8,19]$.

In addition, the effect of the presence of chronic bronchitis in COPD patients on mortality risk is unclear. Although several papers observed an increased mortality risk in COPD patients with chronic bronchitis, it is not clear whether this subgroup of COPD patients is more prone to all-cause mortality or specifically to COPD-related respiratory mortality [20-22]. Furthermore, several studies found different effects of the presence of chronic bronchitis on mortality in males and females [22].

Since previous studies on the association between chronic bronchitis and exacerbations were mainly cross-sectional, clinic-based and provided discordant results, we aimed to investigate the impact of chronic bronchitis on the course of COPD including exacerbations and mortality risk in a prospective population-based cohort study with long-term follow-up, the Rotterdam Study [23].

\section{Methods}

\section{Study design}

The present study is embedded within the Rotterdam Study, a population-based cohort study comprising almost 15000 participants aged $\geqslant 45$ years aiming to assess the occurrence of, and risk factors for, chronic diseases in the elderly [23]. The study started in 1989 and all participants are invited every 3-4 years to the research centre for follow-up examinations, including spirometry. All participants with prevalent COPD and who completed questionnaires on chronic bronchitis during the examination rounds performed between 2001 and 2008 were included. Follow-up time was defined as the time period between the subject's visit to the examination round, and death or end of study period (e.g. January 1, 2013 for the validation of (cause-specific) death), whichever came first. The medical ethics committee of the Erasmus Medical Centre (Rotterdam, the Netherlands), and the review board of the Netherlands Ministry of Health, Welfare and Sports (1068889-159521-PG) approved the study. Participants gave written informed consent.

\section{Assessment of COPD and lung function decline}

The diagnosis of COPD was based on an obstructive prebronchodilator spirometry examination according to the modified GOLD criteria (forced expiratory volume in $1 \mathrm{~s}($ FEV1)/forced vital capacity $(\mathrm{FVC})<0.7)$ or, in the absence of an interpretable spirometry measurement at the research centre, based on diagnosis by a respiratory physician or general practitioner combining clinical history, physical examination and spirometry [24]. Spirometry was performed between 2001 and 2008 using a SpiroPro portable spirometer (Erich Jaeger, Hoechberg, Germany) and from 2009 onwards using a MasterScreen PFT Pro (CareFusion, San Diego, CA, USA) by trained paramedical personnel according to the American Thoracic Society/ 
European Respiratory Society guidelines [25]. Although reversibility tests were not performed in this population-based setting, physician-diagnosed and questionnaire-based asthmatics were excluded. Lung function decline per year was calculated by dividing the difference of the two FEV1 (in millilitres) measurements by the years (days/365.25) between the two measurements. The incident COPD date was defined as the date of the first obstructive lung function or the date of COPD diagnosis in the medical reports or the date of the first prescription of COPD medication, whichever came first.

\section{Assessment of chronic bronchitis}

Chronic bronchitis was assessed by questionnaire and defined as having a productive cough for $\geqslant 3$ months a year during the past 2 years. More specifically, all subjects were questioned [1] "Did you cough nearly daily for three consecutive months during the last 2 years?" and [2] "Did you cough up phlegm nearly daily for three consecutive months during the last 2 years?". Subjects answering negatively to the second question were defined as having no chronic phlegm production $\left(\mathrm{CB}^{-}\right)$. Subjects answering positively to the second question were considered to have chronic phlegm production, but were only defined as having chronic bronchitis when they answered both questions positively $\left(\mathrm{CB}^{+}\right)$.

\section{Assessment of exacerbations}

All COPD subjects were prospectively followed for the onset of exacerbations from their examination visit until death or end of study period (e.g. January 1, 2011 for the validation of exacerbations). Moderate COPD exacerbations were defined as acute episodes of worsening symptoms needing a course of steroids and/or antibiotics. Complete information on all filled prescriptions on a day-to-day basis was obtained in automated format from pharmacies and further validated.

Severe COPD exacerbations were defined as exacerbations requiring a hospitalisation due to COPD. All hospital admissions were continuously registered in the Dutch medical registry and further validated. The exacerbation rate of each patient was defined as the ratio of the total number of exacerbations over the total follow-up time in that patient. COPD subjects with frequent exacerbations were determined as subjects who had at least two (rounded) moderate or severe exacerbations on average per year during follow-up.

\section{Assessment of quality of life and mortality}

Quality of life was based on the EuroQol five-dimension questionnaire (www.euroqol.org; eight questions until 2006; five questions from 2006 onwards), which measures how satisfied/troubled participants are in terms of mobility, ability and activity, self-care, pain and anxiety. A score out of 100 was calculated as the weighted average of scores (minimum=unsatisfied/seriously troubled; maximum=very satisfied/not troubled at all) given to the individual questions. Information on vital status was obtained from general practitioners and from municipal records. Causes of death during follow-up were coded according to the International Classification of Diseases (ICD)-10 [26]. The following categories were applied: pulmonary mortality (ICD-10: J15-J44), cardiac mortality (ICD-10: I21-I73, R96), death from bronchial carcinoma (ICD-10: C34), death from other malignancies (ICD-10: C15-C96 except C34) and other causes of death (ICD-10: all other codes used).

\section{Statistical analyses}

Differences between subjects with and without chronic bronchitis were studied using the Mann-Whitney $\mathrm{U}$-test for continuous variables and Chi-squared test for categorical variables. Logistic and linear regression models were used to calculate the risk of frequent exacerbations and lung function decline, respectively. Cox hazard regression models were used to calculate the time to (cause-specific) death. Models were adjusted for covariates which changed the point estimate of chronic bronchitis on frequent exacerbations by $\geqslant 5 \%$, i.e. age, sex and pack-years of cigarette smoking. Missing pack-years were considered not missing at random and therefore were not imputed. Analyses were stratified according to sex, severity of airflow limitation and the presence or absence of an interpretable lung function measurement at baseline. Sensitivity analyses were performed by extending the $\mathrm{CB}^{+}$group meeting the strict definition towards the broader definition of chronic phlegm production. Statistical analyses were performed using SPSS (version 23.0 for Windows; IBM, North Castle, NY, USA).

\section{Results}

\section{Patient population}

Out of 972 COPD subjects included in the cohort study, 752 subjects with COPD had no chronic phlegm production $\left(\mathrm{CB}^{-}\right)$and 220 subjects had chronic phlegm production, of whom $172(78 \%)$ met the strict criteria of chronic bronchitis $\left(\mathrm{CB}^{+}\right)$(figure 1$) . \mathrm{CB}^{+} \mathrm{COPD}$ subjects were older, more frequently current smokers and had a higher number of pack-years of cigarette smoking (table 1). Furthermore, COPD 


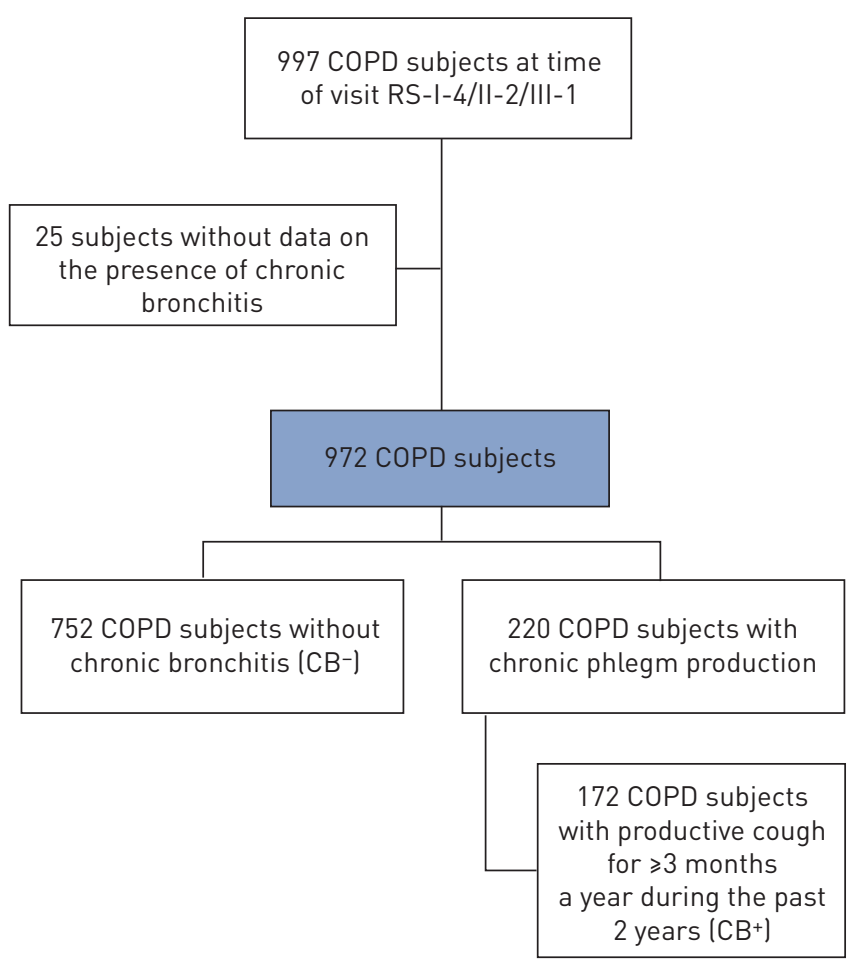

FIGURE 1 Study flow. For additional cohort information see [23]. COPD: chronic obstructive pulmonary disease; RS: Rotterdam Study fourth examination in cohort I/ second examination in cohort II/ first examination in cohort III. f visit RS-1-4/II-2/III-1

5 subjects without data on bronchitis

subjects with chronic bronchitis had a worse lung function at baseline than COPD subjects without chronic bronchitis (table 1). In addition, quality of life was significantly worse in COPD subjects suffering from chronic bronchitis (table 1). Descriptives and analyses performed when extending the $\mathrm{CB}^{+}$group of

TABLE 1 Baseline characteristics of chronic obstructive pulmonary disease subjects without chronic bronchitis $\left(\mathrm{CB}^{-}\right)$and with chronic bronchitis $\left(\mathrm{CB}^{+}\right)$

\begin{tabular}{lccc} 
& CB $^{-}$ & CB $^{+}$ & p-value \\
\hline Subjects n & 752 & 172 & \\
Age years & $70.5(15.2)$ & $74.1(13.6)$ & 0.004 \\
Male & $380(50.5 \%)$ & $96(55.8 \%)$ & 0.211 \\
Smoking status & & & 0.005 \\
$\quad$ Never-smoker & $134(17.8 \%)$ & $17(9.9 \%)$ & \\
$\quad$ Former smoker & $407(54.1 \%)$ & $89(51.7 \%)$ & \\
$\quad$ Current smoker & $211(28.1 \%)$ & $66(38.4 \%)$ & $<0.001$ \\
Cigarette smoking pack-years & $23.0(41.2)$ & $30.6(35.1)$ & 0.529 \\
Height m & $1.69(0.14)$ & $1.68(0.12)$ & 0.082 \\
Weight kg & $76.7(18.8)$ & $74.8(17.3)$ & 0.093 \\
BMI kg-m ${ }^{-2}$ & $26.6(5.3)$ & $26.0(5.5)$ & $<0.001$ \\
FEV $\mathbf{L}$ & $2.0(1.1)$ & $1.8(0.9)$ & $<0.001$ \\
FEV $\%$ pred & $82.0(26.7)$ & $70.5(27.8)$ & 0.034 \\
FVC L & $3.1(1.6)$ & $2.9(1.4)$ & 0.008 \\
FVC \% pred & $101.0(29.5)$ & $91.9(33.0)$ & $<0.001$ \\
FEV $/$ FVC \% & $65.4(7.0)$ & $61.0(10.0)$ & $<0.001$ \\
Quality of life \% & $80.0(21.9)$ & $71.9(31.3)$ & \\
\hline
\end{tabular}

Data are presented as median (interquartile range) unless otherwise stated. Quality of life was based on the EuroQol five-dimensions questionnaire (EQ-5D; www.euroqol.org) measuring how satisfied/troubled participants are in terms of mobility, ability and activity, self-care, pain and anxiety. A score out of 100 was calculated as the weighted average of scores (minimum=unsatisfied/seriously troubled; maximum=very satisfied/not troubled at all) given to the individual questions. Data were missing on pack-years in 46 subjects, height/weight/BMI in 43 subjects, interpretable baseline lung function measurement in 330 subjects and quality of life in 12 subjects. BMI: body mass index; FEV1: forced expiratory volume in $1 \mathrm{~s}$; FVC: forced vital capacity. 
172 subjects meeting the strict definition to the 220 subjects with chronic phlegm production are provided in the online supplementary material.

\section{Impact of chronic bronchitis on lung function and exacerbation rate}

281 out of 972 COPD subjects had an interpretable lung function measurement taken between 2002 and 2008 and a second one between 2009 and 2014. During this median (interquartile range (IQR)) 6.5 (0.8) years of follow-up, COPD subjects with chronic bronchitis had a $38.2 \mathrm{~mL}$ per year greater decline in FEV1 than COPD subjects without chronic bronchitis (95\% CI -61.7--14.6 mL) adjusted for age, sex and pack-years of cigarette smoking (table 2). The excess decline in FEV1 due to chronic bronchitis was $42.8 \mathrm{~mL} \cdot$ year $^{-1}\left(95 \% \mathrm{CI}-78.1--7.6 \mathrm{~mL} \cdot \mathrm{year}^{-1}\right)$ for male COPD CB${ }^{+}$subjects and $36.1 \mathrm{~mL} \cdot \mathrm{year}^{-1}(95 \% \mathrm{CI}$ $-67.1--5.2 \mathrm{~mL} \cdot \mathrm{year}^{-1}$ ) for female $\mathrm{COPD} \mathrm{CB}^{+}$subjects compared to male and female COPD $\mathrm{CB}^{-}$subjects, respectively (table 2). Stratified analyses according to the severity of airflow limitation (i.e. FEV $1 \geqslant 80 \%$ predicted or $<80 \%$ pred) are provided in the online supplementary material. Chronic bronchitis was significantly associated with lung function decline, both in subjects with mild airflow limitation and in subjects with moderate to severe airflow limitation (although the per-millilitre decline was more pronounced in those with milder airflow limitation at baseline) (online supplementary table S2).

During a median (IQR) 5.4 (3.8) years of exacerbation follow-up (until January 1, 2011), COPD $\mathrm{CB}^{+}$subjects had a three times higher median (IQR) rate of moderate to severe exacerbations per year $(0.99$ (1.78) exacerbations per year in the COPD $\mathrm{CB}^{+}$group versus $0.33(0.85)$ exacerbations per year in the $\mathrm{COPD} \mathrm{CB}^{-}$group; $\mathrm{p}<0.001$ ). Additionally, the percentage of COPD subjects who experienced at least one severe exacerbation during follow-up was higher for $\mathrm{CB}^{+}$subjects compared to $\mathrm{CB}^{-}$subjects $(20.3 \%$ versus $7.0 \%$, respectively; $\mathrm{p}<0.001)$. Adjusted for age, sex and pack-years of cigarette smoking, $\mathrm{COPD} \mathrm{CB}^{+}$ subjects had a fourfold increased risk (OR 4.0, 95\% CI 2.7-5.9) of frequent exacerbations (two or more moderate or severe exacerbations per year) (table 3 ). The odds ratio of frequent exacerbations was 3.11 (95\% CI 1.82-5.31) for male $\mathrm{CB}^{+}$subjects and 5.10 (95\% CI 2.83-9.20) for female $\mathrm{CB}^{+}$subjects, compared to male and female COPD $\mathrm{CB}^{-}$subjects, respectively (table 3). Moderate to severe $\mathrm{COPD} \mathrm{CB}^{+}$subjects had a fourfold increased risk of frequent exacerbations compared to moderate to severe $\mathrm{COPD} \mathrm{CB}^{-}$ subjects (online supplementary table S3). In COPD subjects with mild airflow limitation, the effect was less pronounced and chronic bronchitis did not significantly impact the risk of frequent exacerbations.

\section{Impact of chronic bronchitis on all-cause and cause-specific mortality}

During 5856 person-years of follow-up (median (IQR) 6.5 (4.0) years), 351 out of 924 COPD subjects died: 92 (53.5\%) among those with chronic bronchitis and 259 (34.4\%) among those without chronic bronchitis. COPD $\mathrm{CB}^{+}$subjects had a worse survival than $\mathrm{COPD} \mathrm{CB}^{-}$subjects, as illustrated in figure 2 . Compared to $\mathrm{COPD} \mathrm{CB}^{-}$subjects, mortality risk was 1.3 -fold higher in $\mathrm{COPD} \mathrm{CB}^{+}$subjects after adjustment for age, sex and pack-years (HR 1.33, 95\% CI 1.04-1.71) (table 4) and 1.2-fold in mild and 1.4-fold in moderate to severe COPD $\mathrm{CB}^{+}$subjects (online supplementary table S4). Stratified for sex, female $\mathrm{CB}^{+}$subjects had a significantly worse survival than female $\mathrm{CB}^{-}$subjects, while the effect was less pronounced in males and was no longer significant after adjustment for pack-years of cigarette smoking (table 4).

The most frequent causes of death in COPD patients are shown in figure 3 and listed in more detail in online supplementary table S5. Compared to $\mathrm{COPD} \mathrm{CB}^{-}$subjects, $\mathrm{COPD} \mathrm{CB}^{+}$subjects deaths were more

TABLE 2 Association between chronic bronchitis $\left(\mathrm{CB}^{+}\right)$and forced expiratory volume in $1 \mathrm{~s}$ (FEV1) decline

\begin{tabular}{|c|c|c|c|c|}
\hline & \multicolumn{2}{|c|}{ Model 1} & \multicolumn{2}{|c|}{ Model 2} \\
\hline & $\beta(95 \% \mathrm{Cl})$ & p-value & $\beta(95 \% \mathrm{Cl})$ & p-value \\
\hline Subjects $\mathrm{n}$ & 270 & & 259 & \\
\hline $\mathrm{COPD} \mathrm{CB}^{+}$ & $-35.2(-57.9--12.5)$ & 0.002 & $-38.2(-61.7--14.6)$ & 0.002 \\
\hline Male COPD CB ${ }^{+}$ & $-42.8(-77.3--8.2)$ & 0.016 & $-42.8(-78.1--7.6)$ & 0.018 \\
\hline Female COPD $\mathrm{CB}^{+}$ & $-29.4(-58.7--0.05)$ & 0.050 & $-36.1(-67.1--5.2)$ & 0.022 \\
\hline
\end{tabular}

Annual lung function decline $\left(\mathrm{mL} \cdot \mathrm{year}^{-1}\right)$ was calculated by dividing the difference between two $\mathrm{FEV}$ 1 measurements by the number of years between the two measurements. $\beta$-values represent the additional decline of $F E V_{1}$ in chronic obstructive pulmonary disease (COPD) $\mathrm{CB}^{+}$subjects compared to COPD subjects without chronic bronchitis. Model 1: age and sex ${ }^{\#}$ adjusted; model 2: adjusted for age, sex ${ }^{\#}$ and pack-years of cigarette smoking. ${ }^{\#}$ : unstratified analyses only. 
TABLE 3 Association between chronic bronchitis $\left(\mathrm{CB}^{+}\right)$and the frequent exacerbator phenotype

\begin{tabular}{|c|c|c|c|c|}
\hline & \multicolumn{2}{|c|}{ Model 1} & \multicolumn{2}{|c|}{ Model 2} \\
\hline & OR (95\% CI) & p-value & OR (95\% CI) & p-value \\
\hline Subjects n & \multicolumn{2}{|c|}{924} & \multicolumn{2}{|c|}{878} \\
\hline COPD $\mathrm{CB}^{+}$ & $4.13(2.82-6.04)$ & $<0.001$ & $3.96(2.67-5.88)$ & $<0.001$ \\
\hline Male COPD CB ${ }^{+}$ & $3.21(1.90-5.42)$ & $<0.001$ & $3.11(1.82-5.31)$ & $<0.001$ \\
\hline Female COPD CB $^{+}$ & $5.16(2.94-9.05)$ & $<0.001$ & $5.10(2.83-9.20)$ & $<0.001$ \\
\hline
\end{tabular}

Model 1: age and sex" adjusted; model 2: adjusted for age, sex" and pack-years of cigarette smoking. COPD: chronic obstructive pulmonary disease. ${ }^{\#}$ : unstratified analyses only.

frequently due to respiratory-related causes including exacerbations, emphysema or pneumonia (figure 3). COPD $\mathrm{CB}^{+}$subjects had a more than two-fold increased risk of respiratory-related mortality compared to COPD $\mathrm{CB}^{-}$subjects (HR 2.16, 95\% CI 1.12-4.17 adjusted for age, sex and pack-years). Of note, mortality due to lung cancer (bronchial carcinoma) was numerically higher, but did not significantly differ between COPD subjects with and without chronic bronchitis (14.1\% versus $12.4 \%$ ) (figure 3 ).

\section{Discussion}

In this large, population-based cohort study, we demonstrated that COPD subjects with concomitant chronic bronchitis $\left(\mathrm{CB}^{+}\right)$have a worse lung function at baseline and a subsequently larger lung function decline during follow-up. In addition, $\mathrm{COPD}^{\mathrm{CB}^{+}}$subjects experience significantly more exacerbations during follow-up than $\mathrm{COPD} \mathrm{CB}^{-}$subjects. Moreover, this study shows that $\mathrm{CB}^{+}$subjects have a higher mortality risk, especially COPD-related pulmonary death.

In our study, the prevalence of chronic bronchitis in subjects with COPD was $17.7 \%$. The prevalence of subjects in our study with chronic phlegm, with or without the presence of chronic cough, was $22.6 \%$. There is a considerable variability in the prevalence of chronic bronchitis among subjects with COPD reported in other studies, ranging from $7.4 \%$ [19] to $74 \%$ [16]. Several variations of the classical definition have been used to determine chronic bronchitis. In the PLATINO (Latin American Project for Research in Pulmonary Obstruction) study, the prevalence doubled using a less stringent definition [19]. Furthermore, a higher prevalence is reported in patient-based studies, which generally include few patients with mild COPD, whereas population-based studies, such as the Rotterdam study incorporate an unselected COPD population, which generally includes a larger proportion of subjects with mild COPD. Other factors that influence the prevalence of chronic bronchitis among COPD subjects are smoking history and

FIGURE 2 Kaplan-Meier curve of all-cause mortality according to chronic obstructive pulmonary disease without chronic bronchitis (CB $^{-}, \mathrm{n}=752$ ) or with chronic bronchitis (CB $\left.{ }^{+}, \mathrm{n}=172\right)$.

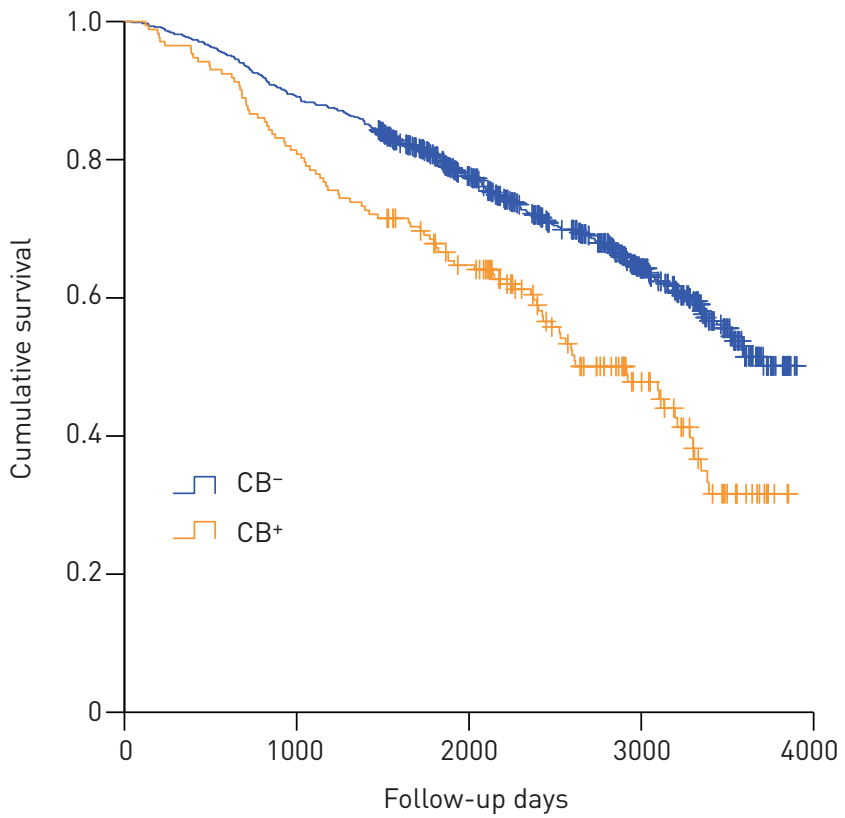


TABLE 4 Association between chronic bronchitis $\left(\mathrm{CB}^{+}\right)$and the risk of all-cause death in chronic obstructive pulmonary disease (COPD), additionally stratified according to sex

\begin{tabular}{llcccr} 
& \multicolumn{2}{c}{ Model 1 } & & \multicolumn{2}{c}{ Model 2 } \\
\cline { 2 - 3 } \cline { 5 - 6 } & HR (95\% Cl) & p-value & & HR (95\% CI) & p-value \\
\hline Subjects n & \multicolumn{1}{c}{924} & & & 878 \\
COPD CB $^{+}$ & $1.45(1.14-1.84)$ & 0.002 & & $1.33(1.04-1.71)$ & 0.024 \\
Male COPD CB & $1.32(0.98-1.78)$ & 0.072 & & $1.22(0.89-1.65)$ & 0.212 \\
Female COPD CB & $1.69(1.14-2.53)$ & 0.010 & & $1.57(1.03-2.40)$ & 0.036 \\
\hline
\end{tabular}

Model 1: age and sex ${ }^{\#}$ adjusted; model 2: adjusted for age, sex ${ }^{\#}$ and pack-years of cigarette smoking. HR: hazard ratio. " : unstratified analyses only.

geographical location $[27,28]$. Lu et al. [28] reported that living in a rural area was associated with an increased risk of the development of chronic bronchitis.

A remarkable observation is that during the follow-up period, $\mathrm{COPD} \mathrm{CB}^{+}$subjects experienced an excess lung function decline of $38.2 \mathrm{~mL} \cdot \mathrm{year}^{-1}$ compared to $\mathrm{COPD} \mathrm{CB}^{-}$subjects. Considering that lung function decline was determined in a subgroup of the population who survived until the next examination round and who had two interpretable measurements, this difference in lung function decline is considerable. The association of chronic bronchitis with a more rapid decline in lung function seemed slightly more pronounced in male $\mathrm{COPD} \mathrm{CB}^{+}$subjects. In line with our findings, the population-based Copenhagen City Heart Study reported an excess decline in FEV1 of $22.8 \mathrm{~mL} \cdot \mathrm{year}^{-1}$ for males and $12.6 \mathrm{~mL} \cdot \mathrm{year}^{-1}$ for females during a 5-year follow-up in COPD $\mathrm{CB}^{+}$subjects, whereas the patient-based ECLIPSE study did not detect a difference in lung function decline in COPD patients with or without chronic bronchitis during a 3-year follow-up, indicating the importance of a relevant follow-up period [8, 29]. In addition, Allinson et al. [30] recently showed in a British cohort study with long-term follow-up, that the presence of chronic bronchitis was associated with an additional $4.5 \mathrm{~mL} \cdot \mathrm{year}^{-1}$ decline in $\mathrm{FEV}$, irrespective of the presence of COPD.

Conflicting results exist regarding the exacerbation rate in $\mathrm{COPD} \mathrm{CB}^{+}$patients. In our study, we observed a significantly increased exacerbation rate and a four-fold increased risk of frequent exacerbations in $\mathrm{COPD} \mathrm{CB}^{+}$subjects compared to $\mathrm{COPD} \mathrm{CB}^{-}$subjects, especially in $\mathrm{COPD}$ subjects with moderate to severe airflow limitation.

Furthermore, an increased exacerbation rate and an increased risk of frequent exacerbations was also reported for COPD $\mathrm{CB}^{+}$subjects in the COPDGene study and in a small study $(\mathrm{n}=70)$ in the UK $[7,14]$. In contrast, the observations from the ECLIPSE study and a patient-based study in Spain did not significantly associate chronic bronchitis to COPD exacerbations [12, 13, 15]. In the population-based PLATINO study, the number of exacerbations in the past year were not significantly different for $\mathrm{CB}^{+}$ subjects compared to $\mathrm{CB}^{-}$subjects, but the percentage of subjects with at least one exacerbation in the past year was significantly higher in the $\mathrm{COPD} \mathrm{CB}^{+}$group compared to the COPD $\mathrm{CB}^{-}$group [19].
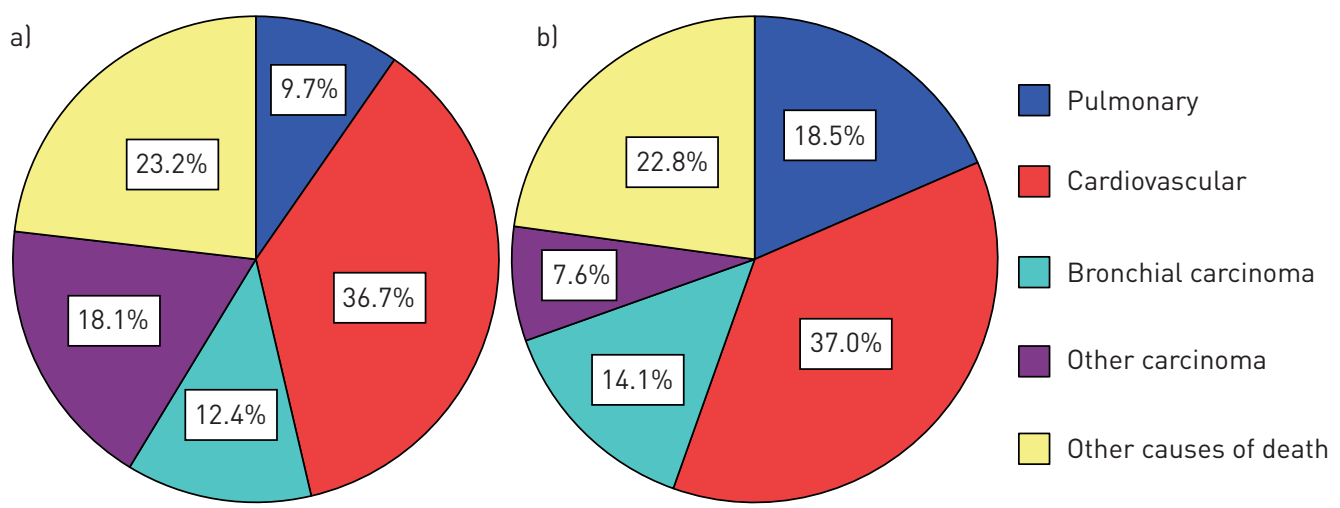

FIGURE 3 Major causes of death according to chronic obstructive pulmonary disease a) without chronic bronchitis ( $\mathrm{n}=752$ ) or b) with chronic bronchitis ( $\mathrm{n}=172$ ). 
Viral and bacterial infections account for the majority of exacerbations in COPD [31, 32]. Observations from the Copenhagen City Heart Study indicate that subjects with chronic bronchitis are indeed more vulnerable to pulmonary infections $[8,21]$. This was also reported in the Lung Health Study, in which subjects with chronic bronchitis reported significantly more lower-respiratory illness than those without chronic bronchitis [33]. These reports strengthen the association between chronic bronchitis and COPD exacerbations.

Potentially due to the increased vulnerability to exacerbations, we observed that COPD $\mathrm{CB}^{+}$subjects are more prone to pulmonary-related death compared to $\mathrm{COPD} \mathrm{CB}^{-}$subjects. Furthermore, in this population, we demonstrated that the presence of chronic bronchitis was associated with an increased all-cause mortality risk of $33 \%$ in COPD subjects. Our results of increased mortality in COPD $\mathrm{CB}^{+}$ subjects are in line with those of PeLKONEN et al. [20], reporting an even higher increase in both all-cause and respiratory-related mortality.

Furthermore, we observed that female $\mathrm{CB}^{+}$subjects had a significantly worse survival than female $\mathrm{CB}^{-}$ subjects. Previous studies have found sex differences in the impact of chronic bronchitis. For example, in the Copenhagen City Heart Study, females with chronic bronchitis experienced more COPD-related hospitalisations than males with chronic bronchitis [8]. In addition, results from the US Six Cities Study indicated that females with chronic bronchitis have an increased risk of COPD-related death, compared to males with chronic bronchitis [34]. Sex differences have been described in the effect of cigarette smoking on lung function and hospitalisation for COPD, with females being more vulnerable to the effects of cigarette smoking [35-37]. Nevertheless, quitting smoking remains key to resolving chronic bronchitis for both males and females [38].

The strengths of our study are the general population-based setting, allowing us to investigate associations in an unselected COPD population, the long-term follow-up and the prospective data collection. In the Rotterdam study, moderate and severe exacerbations are indeed continuously and automatically registered based on pharmacy-filled prescription data and a national hospitalisation register, which prevents recall bias compared to self-reporting of the exacerbation frequency during the previous year in retrospective studies. This does include a limitation, since we have no data on the frequency of mild exacerbations, which are attended by an increase in regular medication.

A second limitation of our study is the fact that lung function was measured on prebronchodilator spirometry and decline could only be determined in a subgroup of the COPD subjects, because an interpretable spirometry at baseline was missing for a subset of subjects, a substantial proportion of the subjects died before lung function could be measured a second time and not all subjects had two interpretable lung function tests. However, even in this smaller group, the difference in lung function decline between COPD subjects with and without chronic bronchitis was significant. Despite the observation of similar results on lung function decline, exacerbation rate and mortality when the $\mathrm{CB}^{+}$ group meeting the strict criteria was extended to all subjects presenting with chronic phlegm production, we do not feel empowered to advocate a broadening of the current definition of chronic bronchitis, because even the very small deviations in effect estimates were towards the null, suggesting that these criteria are indeed more strict in selecting the patients with worse outcomes. Finally, residual confounding in the causal association between chronic bronchitis and worse health outcomes could still be present since, for example, we did not collect information on upper airway infections or gastro-oesophageal reflux.

The results emphasise the importance of recognising chronic bronchitis as a COPD phenotype and the need for therapies that specifically impact the devastating outcomes of COPD subjects with chronic bronchitis. Roflumilast has been shown to be efficacious in patients with severe COPD, frequent exacerbations and a chronic bronchitis phenotype [39]. High dose $\mathrm{N}$-acetylcysteine treatment has been suggested to prevent exacerbations in patients with COPD and chronic bronchitis [40]; however, potential clinical benefits on respiratory health status, lung function or mortality are still controversial [41]. Advantages of novel or already approved antimicrobials are still under investigation (ClinicalTrials.gov including NCT00538148 and NCT01071161).

In conclusion, we have shown that subjects with both COPD and chronic bronchitis have more decline in lung function, experience more exacerbations and worse survival, driven by a higher risk of respiratory-related mortality.

\section{Acknowledgements}

The authors thank the study participants, the staff from the Rotterdam Study and the participating general practitioners. Authors' contributions were as follows. Study design: O.H. Franco, B.H. Stricker and G.G. Brusselle; data collection: L. Lahousse; data analysis: L. Lahousse; writing: L. Lahousse and L. Seys; data interpretation: L. Lahousse, L. Seys and G.G. Brusselle; critical review: G.F. Joos, O.H. Franco, B.H. Stricker and G.G. Brusselle. 


\section{References}

1 Vestbo J, Hurd SS, Agustí AG, et al. Global strategy for the diagnosis, management, and prevention of chronic obstructive pulmonary disease: GOLD executive summary. Am J Respir Crit Care Med 2013; 187: 347-365.

2 Agustí A, Bel E, Thomas M, et al. Treatable traits: toward precision medicine of chronic airway diseases. Eur Respir J 2016; 47: 410-419.

3 Celli BR, Decramer M, Wedzicha JA, et al. An official American Thoracic Society/European Respiratory Society statement: research questions in COPD. Eur Respir J 2015; 45: 879-905.

4 Kim V, Criner GJ. Chronic bronchitis and chronic obstructive pulmonary disease. Am J Respir Crit Care Med 2013; 187: 228-237.

5 Mackay AJ, Hurst JR. COPD exacerbations: causes, prevention, and treatment. Med Clin North Am 2012; 96: 789-809.

6 Miravitlles M, Anzueto A, Legnani D, et al. Patient's perception of exacerbations of COPD - the PERCEIVE study. Respir Med 2007; 101: 453-460.

7 Seemungal TA, Donaldson GC, Paul EA, et al. Effect of exacerbation on quality of life in patients with chronic obstructive pulmonary disease. Am J Respir Crit Care Med 1998; 157: 1418-1422.

8 Vestbo J, Prescott E, Lange P. Association of chronic mucus hypersecretion with FEV1 decline and chronic obstructive pulmonary disease morbidity. Copenhagen City Heart Study Group. Am J Respir Crit Care Med 1996; 153: $1530-1535$

9 Donaldson GC, Seemungal TA, Bhowmik A, et al. Relationship between exacerbation frequency and lung function decline in chronic obstructive pulmonary disease. Thorax 2002; 57: 847-852.

10 Garcia-Aymerich J, Farrero E, Félez MA, et al. Risk factors of readmission to hospital for a COPD exacerbation: a prospective study. Thorax 2003; 58: 100-105.

11 Soler-Cataluña JJ, Martínez-García MA, Román Sánchez P, et al. Severe acute exacerbations and mortality in patients with chronic obstructive pulmonary disease. Thorax 2005; 60: 925-931.

12 Agusti A, Calverley PM, Celli B, et al. Characterisation of COPD heterogeneity in the ECLIPSE cohort. Respir Res 2010; 11: 122.

13 Hurst JR, Vestbo J, Anzueto A, et al. Susceptibility to exacerbation in chronic obstructive pulmonary disease. $N$ Engl J Med 2010; 363: 1128-1138.

14 Kim V, Han MLK, Vance GB, et al. The chronic bronchitic phenotype of COPD: an analysis of the COPDGene study. Chest 2011; 140: 626-633.

15 Izquierdo-Alonso JL, Rodriguez-Gonzálezmoro JM, de Lucas-Ramos P, et al. Prevalence and characteristics of three clinical phenotypes of chronic obstructive pulmonary disease (COPD). Respir Med 2013; 107: 724-731.

16 Burgel PR, Nesme-Meyer P, Chanez P, et al. Cough and sputum production are associated with frequent exacerbations and hospitalizations in COPD subjects. Chest 2009; 135: 975-982.

17 Sundh J, Johansson G, Larsson K, et al. The phenotype of concurrent chronic bronchitis and frequent exacerbations in patients with severe COPD attending Swedish secondary care units. Int J Chron Obstruct Pulmon Dis 2015; 10: 2327-2334.

18 Corhay JL, Vincken W, Schlesser M, et al. Chronic bronchitis in COPD patients is associated with increased risk of exacerbations: a cross-sectional multicentre study. Int J Clin Pract 2013; 67: 1294-1301.

19 Montes de Oca M, Halbert RJ, Lopez MV, et al. The chronic bronchitis phenotype in subjects with and without COPD: the PLATINO study. Eur Respir J 2012; 40: 28-36.

20 Pelkonen M, Notkola IL, Nissinen A, et al. Thirty-year cumulative incidence of chronic bronchitis and COPD in relation to 30-year pulmonary function and 40-year mortality: a follow-up in middle-aged rural men. Chest 2006; 130: 1129-1137.

21 Prescott E, Lange P, Vestbo J. Chronic mucus hypersecretion in COPD and death from pulmonary infection. Eur Respir J 1995; 8: 1333-1338.

22 Kim V, Criner GJ. The chronic bronchitis phenotype in chronic obstructive pulmonary disease: features and implications. Curr Opin Pulm Med 2015; 21: 133-141.

23 Hofman A, Brusselle GG, Darwish Murad S, et al. The Rotterdam Study: 2016 objectives and design update. Eur J Epidemiol 2015; 30: 661-708.

24 Terzikhan N, Verhamme KM, Hofman A, et al. Prevalence and incidence of COPD in smokers and non-smokers: the Rotterdam Study. Eur J Epidemiol 2016; 31: 785-792.

25 Celli BR, MacNee W. Standards for the diagnosis and treatment of patients with COPD: a summary of the ATS/ ERS position paper. Eur Respir J 2004; 23: 932-946.

26 World Health Organization (WHO). International Statistical Classification of Diseases and Health Related Problems. 10th revision. Geneva, WHO, 1992. www.who.int/classifications/icd/en/ Date last accessed: June 21, 2017. Date last updated: November 11, 2017.

27 Dijkstra AE, de Jong K, Boezen HM, et al. Risk factors for chronic mucus hypersecretion in individuals with and without COPD: influence of smoking and job exposure on CMH. Occup Environ Med 2014; 71: 346-352.

$28 \mathrm{Lu} \mathrm{M}$, Yao W, Zhong N, et al. Chronic obstructive pulmonary disease in the absence of chronic bronchitis in China. Respirology 2010; 15: 1072-1078.

29 Vestbo J, Edwards LD, Scanlon PD, et al. Changes in forced expiratory volume in 1 second over time in COPD. N Engl J Med 2011; 365: 1184-1192.

30 Allinson JP, Hardy R, Donaldson GC, et al. The presence of chronic mucus hypersecretion across adult life in relation to chronic obstructive pulmonary disease development. Am J Respir Crit Care Med 2016; 193: 662-672.

31 Sethi S, Murphy TF. Infection in the pathogenesis and course of chronic obstructive pulmonary disease. $N$ Engl J Med 2008; 359: 2355-2365.

32 Papi A, Luppi F, Franco F, et al. Pathophysiology of exacerbations of chronic obstructive pulmonary disease. Proc Am Thorac Soc 2006; 3: 245-251.

33 Kanner RE, Anthonisen NR, Connett JE. Lower respiratory illnesses promote FEV1 decline in current smokers but not ex-smokers with mild chronic obstructive pulmonary disease: results from the Lung Health Study. Am J Respir Crit Care Med 2001; 164: 358-364.

34 Speizer FE, Fay ME, Dockery DW, et al. Chronic obstructive pulmonary disease mortality in six U.S. cities. Am Rev Respir Dis 1989; 140: S49-S55. 
35 Barnes PJ. Sex differences in chronic obstructive pulmonary disease mechanisms. Am J Respir Crit Care Med 2016; 193: 813-814.

36 Prescott E, Bjerg AM, Andersen PK, et al. Gender difference in smoking effects on lung function and risk of hospitalization for COPD: results from a Danish longitudinal population study. Eur Respir J 1997; 10: 822-827.

37 Celli B, Vestbo J, Jenkins CR, et al. Sex differences in mortality and clinical expressions of patients with chronic obstructive pulmonary disease. The TORCH experience. Am J Respir Crit Care Med 2011; 183: 317-322.

38 Kim V, Zhao H, Boriek AM, et al. Persistent and newly developed chronic bronchitis are associated with worse outcomes in chronic obstructive pulmonary disease. Ann Am Thorac Soc 2016; 13: 1016-1025.

39 Martinez FJ, Calverley PM, Goehring UM, et al. Effect of roflumilast on exacerbations in patients with severe chronic obstructive pulmonary disease uncontrolled by combination therapy (REACT): a multicentre randomised controlled trial. Lancet 2015; 385: 857-866.

40 Cazzola M, Calzetta L, Page $\mathrm{C}$, et al. Influence of $\mathrm{N}$-acetylcysteine on chronic bronchitis or COPD exacerbations: a meta-analysis. Eur Respir Rev 2015; 24: 451-461.

41 Johnson K, McEvoy CE, Naqvi S, et al. High-dose oral N-acetylcysteine fails to improve respiratory health status in patients with chronic obstructive pulmonary disease and chronic bronchitis: a randomized, placebo-controlled trial. Int J Chron Obstruct Pulmon Dis 2016; 11: 799-807. 